\title{
Obituaries
}

\section{Sir Richard Doll}

\author{
Epidemiologist who showed that smoking caused cancer and heart disease
}

Sir Richard Doll was the world's most distinguished medical epidemiologist. He established his reputation alongside Sir Austin Bradford Hill, showing that cigarette smoking caused lung cancer. He then went on to show it caused bladder and other cancers, and cardiovascular disease. He did seminal work with Richard Peto on the health of doctors and their families, demonstrating an increased incidence of suicide and liver disease. He also carried out major research on the risks and benefits of the contraceptive pill, on low level radiation, and the dietary treatment of gastric ulcers.

Doll went to work with Bradford Hill at the Medical Research Council in January 1948. Government statisticians had drawn the MRC's attention to a huge recent increase in lung cancer deaths, and the MRC held a conference to decide whether the increase was real and, if so, whether a cause could be identified.

At the time, said Doll, smoking seemed a normal and harmless habit. Eighty per cent of men smoked. Doll and Hill both thought the most likely cause would prove to be pollution-smuts from coal fires were terrible in those days, but had been for decades, and the expansion of the motor industry had meant more tarring of roads, and more exhaust fumes. There was a known association of pipe smoking with lip cancer, but that was thought to be caused mainly by the heat of the pipe stem.

Doll and Hill designed a short questionnaire, administered by social workers, to 650 male patients in London hospitals. The interviewees were newly admitted patients with suspected lung, liver, or bowel cancers. To reduce bias, the interviewers were not told the suspected diagnosis. They also interviewed hospital patients with other diagnoses. After the proper diagnoses had been made, it was startlingly clear that those whose lung cancer was confirmed were smokers, and those who were given the all clear were non-smokers.

The results were so compelling and so unexpected that Doll and Hill took the results to the MRC head Sir Harold Himsworth, who advised them that the results might be peculiar to London, and suggested that they repeat the study in other

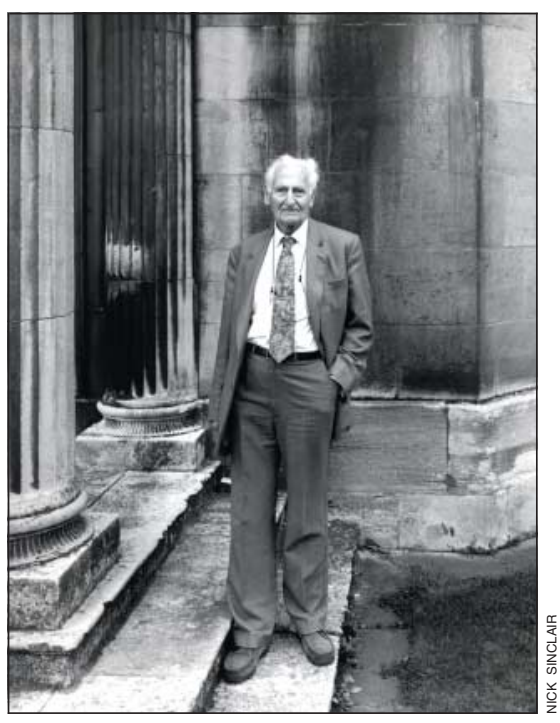

tician, who disputed Doll and Hill's findings. Five years later the statistician told his employers that unless they accepted that tobacco smoking caused cancer he could not work for them any longer.

William Richard Shaboe Doll was born in Hampton, Middlesex, the son of a general practitioner. During the second world war he served in France and the Middle East and took part in the invasion of Sicily. Doll's Dunkirk diary, detailing his experiences as a battalion medical officer in the retreat to Dunkirk, was published in instalments in the $B M J$ in 1990 .

Doll contracted renal tuberculosis in the middle of 1944 and was discharged early in 1945 after a nephrectomy. He convalesced by working as a psychiatrist in an army hospital for six months before returning to $\mathrm{St}$ Thomas' as a junior medical assistant.

The 1950 BMJ paper on smoking and lung cancer was largely ignored by the public. The Department of Health's cancer committee was not convinced by the findings and thought that urging people to quit could start a mass panic. Finally, on 12 February 1954, the health minister Iain Macleod held a conference to announce that the government accepted the link. He famously chain smoked throughout the event. The Royal College of Physicians brought out a report in 1962 that linked smoking and death, and this turned the tide of public opinion.

Doll, who was at one stage a smoker, but gave up when he discovered the association with lung cancer, remained well and productive until nearly the end of his life.

Predeceased by his wife, Joan Faulkner, he leaves a son and a daughter. [CAROLINE Richmond]

William Richard Shaboe Doll, epidemiologist Medical Research Council 1946-69 and regius professor of medicine Oxford University 1969-79 (b 1912; q St Thomas'Hospital, London, 1937; CH, OBE, FRS, DSc, MD, DM, FRCP, FFPHM), d 24 July 2005. were 200 , almost all of them in heavy smokers. The incidence in non-smokers was negligible. Doll and Hill began publishing their results in the BMJ in 1954 (BMJ 1954;228(i): 1451-5).

It was not long before they were visited by two men from the tobacco industry-the chairman of Imperial Tobacco and his statis-
Doll and Hill's 1954 BMJ paper, "The mortality of doctors in relation to their smoking habits: a preliminary study," is available in PDF format at http://bmj.bmijournals.com/ cgi/reprint/328/7455/1529 


\section{Walter Vincent Anderson}

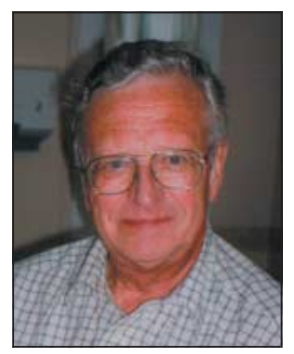

Former general practitioner Scarborough (b Blyth 1934; q Newcastle 1958; FRCGP), d 24 June 2005.

After preregistration posts at the Royal Victoria Infirmary in Newcastle Walter started his career in obstetrics. He then became an associate in general practice in Birmingham, but in 1966 relocated to Edinburgh University as a lecturer in general practice. In 1967 he settled in Scarborough, remaining a partner in a general practice there until 1994. He was also a clinical assistant in ear, nose, and throat medicine at Scarborough Hospital, but is better remembered for his contribution to teaching in general practice and helping to make it a specialty in its own right. Predeceased by his first wife, Jean, he leaves his second wife, Sue; two children; and four grandchildren. [SALLy ANDERson]

\section{D’Almero ("Darrell") Kok}

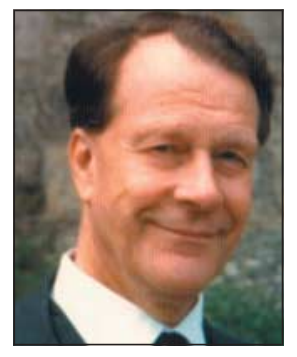

Research haematologist and honorary consultant Addenbrooke's Hospital, Cambridge (b South Africa 1920; q St Bartholomew's Hospital, London, 1944: MD, FRCP), d 29 April 2005.

D'Almero Kok, known as Darrell, began studying medicine at Witwatersrand University, South Africa, at the age of 15, moving to London as a clinical student at 18. After house jobs during the second world war he gained his MD in 1945. His national service as a Royal Army Medical Corps pathologist in Hamburg from 1946 to 1948 included carrying out autopsies for evidence for the Nuremberg trials. In 1955 he became a lecturer in medicine at Cambridge University and honorary consultant physician at Addenbrooke's. Delays in the opening of Cambridge's clinical school diverted Darrell into research on platelets and blood flow, while caring for lymphoma patients from all over East Anglia. He retired in 1987 to nurse his disabled wife, Pamela. He leaves Pamela and two sons. [Nigel Gibbons]
Douglas Macdonald McKean

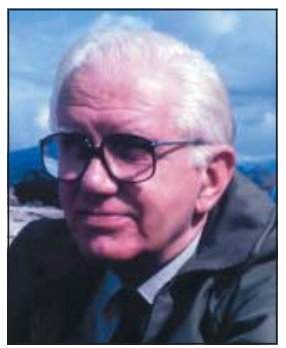

Former general practitioner Kingston upon Hull (b Glasgow 1925; q Glasgow 1947), d 13 March 2005.

"Dougie," as he was known, did one year of pharmacy before entering medical school. He did national service in the Royal Air Force and then became a trainee in a general practice in Partick. In 1952 he became an assistant in a dockside practice in Hull. He was soon made a partner, remaining until retirement. The practice grew steadily in size under his inspiration from 3000 patients in the early 1960s to 18000 and seven partners in the late 1980s. Dougie took up pottery, building his own kiln. He leaves a wife, twin daughters, and two granddaughters. [PETER Jones]

\section{Robert Martin Rowan}

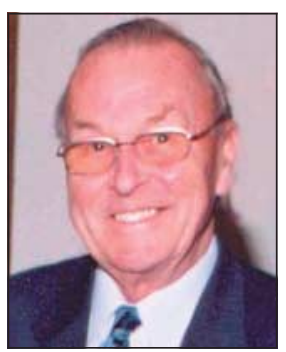

Former consultant haematologist Glasgow (b Dumfries 1935; q Edinburgh 1957; FRCP Glas, FRCP Ed, FRCPath), died from colon cancer on 4 May 2005.

Martin Rowan became a consultant in haematology at the Glasgow Royal Infirmary in 1969, and in 1977 he was appointed head of the haematology department at the Glasgow Western Infirmary and senior lecturer in haematology at the University of Glasgow until his retirement in 1996. He researched laboratory instrumentation, especially the potential developments in automated analysers, realising their future role in the organisation of modern laboratory practice. This was to be his life study. Under his direction his department gained an international reputation as a centre of excellence for the evaluation, standardisation, and quality control of laboratory instruments, and the clinical reliability of laboratory tests. He leaves a wife, Betty, and two children. [MitcheLl Lewis]

\section{Agnes Hallimond Wilkinson (née Crozier)}

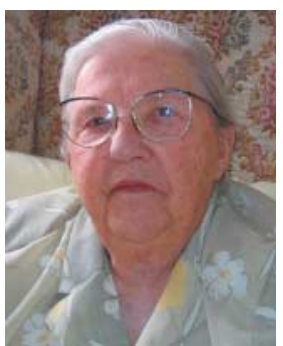

Former psychotherapist London (b South Africa 1915; q Birmingham 1939; MRCP;FRCPsych), died on 19 June 2005 following a stroke.

After qualifying Agnes Wilkinson (nicknamed "George") was house physician to Professor K D Wilkinson. Despite a 30 year age difference, they were married in 1941 and she acquired four stepchildren. She was widowed in 1951 and moved to Bristol, where she became physician in charge of student health and developed an interest in psychotherapytraining as an analytic psychotherapist. In 1960 she moved to London and entered full time practice as a psychotherapist, retiring in 1986. She remained active in retirement, doing a postgraduate course in gerontology. She leaves a stepson, two daughters, and a son. [JAMES WiLKINSON]

\section{Fiona Margaret Wilson}

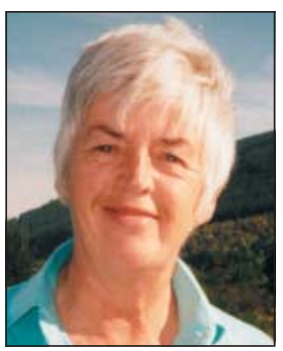

Psychiatrist and former general practitioner Northumberland and Edinburgh (b Perth 1932; $q$ Glasgow 1955), died from adenocarcinoma on 20 April 2005.

After posts in anaesthetics and chest medicine Fiona moved with her husband, a consultant psychiatrist, to the north of England. Following some years in general practice near Carlisle and Blyth, she became an assistant psychiatrist at Northgate and District Hospital, Morpeth, and St Nicholas Hospital, Newcastle upon Tyne. In 1977 they returned to her beloved Scotland, where she was a senior clinical medical officer in community care in learning disability and multiple handicap for Edinburgh and Lothian. She leaves a husband, Olly; three sons; and five grandchildren. [WILLIAM Fraser, IAN Airlie, Olly Wilson]

Longer versions of these obituaries are available on bmj.com 